\title{
ДИСКУССИИ
}

\section{Развитие стейкхолдерского подхода в методологии финансового анализа: гармоничная компания}

\author{
Ивашковская И.В. ${ }^{15}$
}

В статье рассматривается авторская конџепция гармоничной компании, отвечающая принциипам стейкхолдерского подхода к фирме. Обосновано положение о формировании архитектуры капитала, представляющей собой новый тип структуры капитала фирмы. Показано, что архитектура капитала предполагает новое стоимостное мышление $u$ оценку изменений стоимости для стратегических нефинансовых стейкхолдеров, а также требует новых инструментов для финансовых измерений.

\section{JEL: G320}

Ключевые слова: стейкхолдерский подход, финансовый анализ, гармоничная компания, архитектура капитала, стоимостное мышление

Изменения процессов в фирме в условиях перехода к инновационной экономике ставят существенные задачи в области финансового анализа компании. Необходимы смена парадигмы финансового анализа компании и формирование на ее основе новой модели управления стоимостью компании. Решение первой задачи предполагает трансформацию контекста и расширение поля финансового анализа. Кардинальные сдвиги, вызванные движением к инновационной экономике, предопределяют совокупность изменений в анализе капитала, конфликтов интересов, возникающих при его использовании, и в конечном счете в анализе агрегированного финансового результата компании. Вопросы новых подходов к финансовому анализу компании уже ставились автором в ряде работ (Ивашковская, 2008а; Ивашковская, 2008б; Ивашковская, 2008в). Смена парадигмы анализа фирмы предполагает переосмысление сути существующих в ней отношений, целей, инструментов их достижения, ответственности участников процесса за их реализацию.

В теоретической экономической и управленческой литературе отмечается, что основным источником знаний, стимулирующих коренные изменения во взглядах на принципы функционирования фирм, стало понимание ее новой роли в социальноэкономической структуре общества, признание узости анализа с позиций акционеров и активизация дискуссий о роли более широкого круга стейкхолдеров (Клейнер, 2008a, с. 306; Zingales, 2000; Charreaux, Desbrieres, 2001). Вектор развития финансового анализа связан с проблематикой создания добавленной стоимости для стейкхолдеров (stakeholder value added, STVA). Такое целеполагание для компании вместо задачи наращения стоимости акционерного капитала настроено на достижение гармонии множественных интересов разных категорий стейкхолдеров, выражающейся в приросте стоимости для стейкхолдеров. Этому процессу соответствует становление гармоничной компании. Для исследования коренных характеристик гармоничной компании целесообразно подытожить ключевые аргументы, обсуждаемые в рамках стейкхолдерского подхода.

Учитывая важность проблематики роли стейкхолдеров компании, западные исследовательские центры в конце 1990-х годов инициировали проекты, направленные на изучение происходящих изменений. Первый ракурс дискуссий связан с формированием

\footnotetext{
15 Д-р эконом. наук, зав. кафедрой экономики и финансов фирмы, зав. Лабораторией корпоративных финансов
} НИУ ВШЭ. 
нового видения сути корпоративной формы организации бизнеса как таковой. Переосмысление сути корпорации XXI века основано не только на растущих размерах таких компаний, глобализации их операций и масштабе их влияния на целые отрасли экономики, но главное - на новом понимании отношений собственности. Сложилась трактовка, признающая существенные изменения, вызванные переходом к инновационной экономике, во взглядах на позицию акционеров как субъектов отношений собственности и корпорации (акционерной компании) как объекта.

В специальном обобщающем выпуске, посвященном 75-летию журнала Harvard Business Review, выдвинута точка зрения о том, что понимание корпорации как объекта собственности держателей акций неполно и неверно, так как не определяет, кому же принадлежит власть. Корпорацию следует рассматривать не как элемент имущественных прав, а скорее как сообщество, созданное для достижения общих целей (Handy, 1997). В акционерном законодательстве, как отмечают зарубежные исследователи в области права, корпоративного управления и роли советов директоров, не удается найти прямые свидетельства того, что акционеры имеют безусловный приоритет и что они являются собственниками компании как таковой. Владение акцией не означает, что акционер является собственником конкретной группы активов (Deakin, 1995). Законодательно не устанавливается ни норма доходности, к которой компания должна стремиться, ни срок, в течение которого ожидания акционеров по доходам должны быть достигнуты. В британском корпоративном праве и законодательстве других стран, базирующихся на его принципах, показано, что фидуциарные обязанности членов советов директоров существует перед компанией, а не непосредственно перед ее акционерами. Акционерам не предписано прямое право вовлекаться в управление компанией. Организация управления и контроль над ним это функция совета директоров.

Наиболее отчетливо эти акценты расставлены в корпоративном праве штата Делавер (США). В начале XXI века в британское законодательство внесены поправки, которые расширяют представления о задачах советов директоров в направлении достижения интересов стейкхолдеров и предписывают директорам соответствующий набор функций (Modern Company Law for a Competitive Economy, 2002).

Примером инициативных проектов «переосмысления корпорации» является группа проектов на основе гранта фонда А. Слоуна (Post, Preston, Sauter-Sachs, 2002; The Corporation and Its Stakeholders, 1998; Principles of Stakeholders Management, 1999). Данные работы выдвинули ряд существенных положений, в которых, по мнению их авторов, и состоит суть переосмысления акционерной формы (корпорации) как явления в существенно изменяющейся экономике. Как отмечают авторы Слоуновского проекта «Пересмотр корпоративной формы», выполненного в университете Стэнфорд, существующая точка зрения о том, что акционеры владеют корпорацией, неаккуратна: «Акционеры являются собственниками ценных бумаг, но они не владеют корпорацией как юридическим лицом ни в каком из имеющихся значений и не составляют единственной группы, чьи интересы жизненно необходимо соблюдать для достижения еe успеха» (Post, Preston, Sauter-Sachs, 2002 , p. 11). Второе важное положение заключается в том, что корпорация представляет собой «центр сетевых взаимодействий взаимосвязанных интересов и участников, каждый из которых добровольно или вынужденно вносит вклад в ее результативность, получая выгоды (или по крайне мере не нанося ущерба своим интересам) от деятельности корпорации» (Post, Preston, Sauter-Sachs, 2002, p. 8).

Успех корпораций в новом веке и в новых экономических и конкурентных условиях базируется в значительной степени на регулярном отслеживании этой системы интересов. Поэтому в определении современной фирмы, разработанном по результатам проектов фонда А. Слоуна, подчеркивается, что ее следует рассматривать как «организацию, занимающуюся мобилизацией ресурсов для создания благосостояния и других форм выгод для разнообразных стейкхолдеров, не позволяя намеренно разрушать их благосостояние, увеличивать риск и наносить им ущерб» (Post, Preston, Sauter-Sachs, 2002, p. 17). Таким 
образом, суть нового видения корпоративной формы организации фирмы состоит в необходимости оценки ее деятельности с точки зрения всех групп стейкхолдеров, а не только собственников. Оценка результатов критериями собственников (акционеров) недостаточна. Представленная в проекте фонда А. Слоуна трактовка согласуется с принципами, обсуждаемыми Организацией экономического сотрудничества и развития (ОЭСР) в связи с необходимостью анализа новых процессов в корпоративном управлении.

Второй ракурс обоснований связан с аргументами новых постановок в контрактной теории фирмы, разрабатываемых после выхода работ О. Харта и Дж. Мура (Hart, Moore, 1990), П. Агиона и П. Болтона (Aghion, Bolton, 1992). В отличие от традиционной контрактной теории, в указанных работах была в явной форме введена предпосылка неполных контрактов. В соответствии с вариантом контрактной теории, формирующимся на этой основе, фирма рассматривается как совокупность не только явных (explicit), как в случае традиционной трактовки, но и неявных (implicit) контрактов. Как отмечают К. Эшер, Дж.М. Махоней и Дж.Т. Махоней, важны следующие аргументы. Во-первых, сами акционеры не являются полностью защищенными явными контрактами. Это подрывает теоретическую предпосылку, господствовавшую до сих пор, о приоритете акционеров в области остаточных прав контроля над ресурсами фирмы. Во-вторых, не только акционеры, но и нефинансовые стейкхолдеры находятся в состоянии незащищенности явными контрактами и вытекающей отсюда экспроприации их благосостояния (Asher, Mahoney, Mahoney, 2005). Как подчеркивает Л. Зингалес, если придерживаться точки зрения о фирме как пучке полных явных контрактов, это будет означать узость взгляда на суть контрактов и игнорирование реальных факторов, говорящих о существенном влиянии права акционеров на принятие решений, влияющих на потоки экономических выгод для остальных стейкхолдеров (Zingales, 2000).

Третий ракурс представлен аргументами сторонников концепции прав собственности (property rights), выдвигающих ее как основу обновления теории фирмы. Аргументы, приводимые в работах К. Эшера, Дж.М. Махонея и Дж.Т. Махонея, Т. Дональдсона и Л. Престона, Р. Агиэра, Г. Джэксона и А. Куэрво-Казурра, близки к принципам новой контрактной теории (Asher, Mahoney, Mahoney, 2005; Aguilera, Jackson, 2003; Aguilera, Cuervo-Cazurra, 2004; Donaldson, Preston, 1995). С точки зрения сторонников концепции прав собственности, необходимо переосмысление ресурсной трактовки фирмы, которое они предлагают реализовать путем интеграции этих двух подходов. Во-первых, отмечается, что нерешенными остаются вопросы прав собственности акционеров на такие нематериальные ресурсы, как интеллектуальные (разные формы знаний), организационные (разные виды практик). Современные правовые системы эффективно решают проблемы собственности на материальные ресурсы, но в них сохраняются противоречия и нерешенные вопросы относительно нематериальных ресурсов, используемых в компании. Во-вторых, не изучены пока фундаментальные изменения в оптимальных формах организации фирмы, отвечающих необходимости применения специфических нематериальных ресурсов. Поэтому в работах этого направления отмечается проблема прав контроля над специфическими ресурсами, механизмов такого контроля и места в этом процессе советов директоров компании. Учитывая эти противоречия, сторонники соединения ресурсной теории и концепции прав собственности отмечают, что решение отмеченной проблемы невозможно в рамках парадигмы приоритета интересов акционеров.

Уникальность ресурсов, предоставляемых нефинансовыми стейкхолдерами, и разделение ими рисков с финансовыми стейкхолдерами служит основанием для того, чтобы рассматривать их как специфических инвесторов. Специфика инвестиций связана с тем, что ресурсы стейкхолдеров относятся, как правило, к категории непередаваемых (Charreaux, Desbrieres, 2001, p. 115) и уникальных, невоспроизводимых. Данные особенности означают, что нефинансовые стейкхолдеры должны рассматриваться в качестве обладателей остаточных требований к компании и участвовать в принятии корпоративных решений, как и финансовые инвесторы (Stakeholder Capitalism, 1997). 
Аналогичные выводы о включении ключевых нефинансовых стейкхоледров в состав группы, определяющей решения о правилах использования ресурсов и о регламентах их изменения, делаются в известных работах, формирующих ядро дискуссии в стейкхолдерском подходе (Mitchell, Agle,Wood, 1997; Luoma, Goodstein, 1999; Frooman, 1999; Pajunen, 2006). Рассматривая специфические инвестиции стейкхолдеров в компанию, М. Блэр подчеркивает, что в области корпоративного права необходимо ставить проблему «принятия решения командой» (team production), как адекватного изменившимся условиям механизма принятия решений. В состав такой команды, наделенной правами принятия решения, должны включаться стейкхолдеры, осуществившие специфические инвестиции. Результаты таких специфических инвестиций зависят от совокупных результатов фирмы, и это создает основания для права на участие в принятии решений (Blair, Stout, 1999).

В ситуациях специфических инвестиций рыночные механизмы неэффективны и не могут использоваться как инструменты распределения создаваемых экономических рент (Blair, 1995). Такая аргументация, как подчеркивает В.Л. Тамбовцев, формирует отдельное направление в теории прав собственности: концепции прав собственника (Тамбовцев, 2008). Поэтому права на принятия решений передаются советам директоров от имени всех инвесторов, сделавших такие специфические инвестиции. В области корпоративного права, по мнению М. Блэр, предстоит переосмысление акцентов и их смещение в зону прав собственности от контрактного права, которое является пока доминирующей зоной. Поэтому интеграция подходов в праве с подходами в стратегическом менеджменте, где была поставлена проблема стейкхолдерского подхода к фирме, продуктивна именно на почве концепций прав собственника и поиска мест стейкхолдеров в этих трактовках.

Сведение процесса создания стоимости в условиях перехода к инновационной экономике к проблеме остаточного характера прав акционеров как поставщиков финансового капитала и необходимости создания для них экономической ренты не дает правильной интерпретации изменяющегося процесса. Дело не просто в том, что решения, принимаемые в фирме, затрагивают интересы нефинансовых категорий стейкхолдеров (Charreaux, Desbrieres, 2001, p. 107). Этот аргумент отмечается практически во всех работах, где рассматривается проблематика стейкхолдерского подхода в менеджменте. Однако его недостаточно. Существенно, что фирма более не может рассматриваться как сумма компонентов, имеющихся по- отдельности на разных видах рынков, привлеченных контрактными механизмами. Важным свойством фирмы становится комбинация специализированных и комплиментарных активов, которая формируется внутри фирмы, ведет к созданию нового знания и нового качества отношений, не может объясняться наличием явных контрактов (Baker, Gibbons, Murphy, 2001).

Во-вторых, формирование системного контура нефинансовых форм капитала выводит проблему роли стейкхолдеров за рамки ракурса поставщика ресурсов и за пределы поля аргументации контрактной теории и ее аргумента об остаточных правах владельцев акционерного капитала на доход и на контроль над всеми ресурсами компании в соответствии с заключенными ею контрактами. Существенно, что нефинансовых стейкхолдеров необходимо рассматривать как владельцев специфических видов капитала. При этом проблема собственности на такие виды капитала как таковая в академических работах не решена. Отработаны концепции прав интеллектуальной собственности, но этой группой объектов отнюдь не исчерпывается понятие интеллектуального капитала. Не развита и трактовка социального капитала. Как отмечает Г.Б. Клейнер, анализ фирмы как социально-экономической системы потребует более полного изучения состава стейкхолдеров и включения в него значительно более широкого круга инвесторов в подсистемы фирмы: интеллектуальных инвесторов (сфера вложения - ментальная подсистема), культурных доноров (сфера вложения - культурная подсистема), институциональных инвесторов (сфера вложения - институциональная подсистема), когнитивных инвесторов (сфера вложения - когнитивная подсистема), имитационных доноров (сфера вложения - имитационная подсистема) (Клейнер, 2008, с. 190). 
Однако отсутствие единства мнений и фундаментальных теоретических трудов с решениями этих вопросов не снимают с повестки дня самих явлений. Перспектива развития новых теорий фирмы не может не быть связанной с разработками именно в области собственности на интеллектуальный и социальный капиталы. Считая рассмотренный выше аргумент о неявных контрактах некорректным, В.Л. Тамбовцев, тем не менее, подчеркивает, что ценовые и иные механизмы регулирования, которые обычно являются средствами защиты от неопределенности результатов контрактов, неприменимы к владельцу актива в принципе, так как бессмысленно заключать контракт с самим собой. Именно поэтому владельцу актива нужна дополнительная защита в виде остаточных прав (Тамбовцев, 2008, с. 13).

Однако корень проблемы состоит как раз в том, что в условиях перехода к инновационной экономике успешная бизнес-модель компании не может быть построена без интеллектуального и социального капиталов. При переходе к инновационной экономике формируется новый системный контур нефинансового капитала в фирме, включающий интеллектуальный и социальный капиталы. Ему свойственен особый характер взаимосвязей между его составными элементами и конкурентоспособностью компании в условиях смены характера экономики. Системный контур нефинансовых форм капитала охватывает комбинации специфических ресурсов, создающих уникальные и невоспроизводимые эффекты в самом процессе производства и продвижения продукта и формирует коренные конкурентные преимущества компании.

Образование системного контура нефинансового капитала не только ведет к расширению поля финансового анализа компании, но и выступает катализатором смены представлений о его содержании и инструментарии. Развитие финансовой модели анализа компании должно быть связано со следующими направлениями: во-первых, с введением в дополнение к финансовым измерениям компании нового контура - стратегических нефинансовых стейкхолдеров, создающих нефинансовые формы капитала; во-вторых, с новым видением взаимодействия интересов стейкхолдеров, определяющих их мотивацию, влияние на инвестиционные риски компании и на создание ее стоимости; в-третьих, с новым подходом к анализу агрегированного результата деятельности компании - с введением оценки стоимости для стейкхолдеров (stakeholder value, STV). Поэтому стейкхолдеры более не могут рассматриваться лишь как участники контрактов, получающих вознаграждение в соответствии с их условиями.

Таким образом, создание гармоничной компании предполагает обеспечение согласования элементов множества интересов финансовых и нефинансовых стейкхолдеров, формирующихся в пространстве взаимодействия трех форм капиталов - финансового, интеллектуального и социального - и в разрезе краткосрочных и долгосрочных горизонтов их реализации.

Для понимания гармоничной компании множество интересов стейкхолдеров надо классифицировать (в соответствии с их интересами) на подсистемы (кластеры) финансового, интеллектуального и социального капиталов. Несовпадения и противоречия интересов существуют как в подсистеме интересов финансовых стейкхолдеров компании, так и в подсистемах интеллектуального и социального капиталов. Горизонт инвестиций у портфельного, миноритарного инвестора и спектр его задач существенно иные, чем у стратегического, мажоритарного. Портфельный инвестор сориентирован на быстрый рост своего дохода в виде прироста стоимости акций, в то время как для стратегического нужен долгосрочный тренд их роста. Несмотря на внутренние разногласия между интересами внутри группы собственников компании, интересы и миноритарных, и мажоритарных инвесторов могут противостоять целям и пониманию выгод кредиторами компании. Ущемление интересов последних за счет перетока стоимости в пользу собственников - одна из популярных тем в теории корпоративных финансов.

Вторую подсистему формируют интересы стейкхолдеров, являющихся носителями интеллектуального и социального капиталов. Формально в их составе могут быть разные 
категории стейкхолдеров: менеджмент, персонал, клиенты, поставщики, корпоративные директора. Например, первые создают особые знания, разрабатывая систему стратегических решений, выстраивая бизнес-процессы и управленческие рутины, приспособленные к специфике компании. Последние создают стратегическое видение, или собственно будущую специфику компании, процедуры контроля его реализации. Отличительная особенность интересов носителей интеллектуального капитала состоит в том, что эти группы стейкхолдеров заинтересованы не только в вознаграждении за вклад в формирование интеллектуального капитала и в результаты деятельности компании, но и мотивированы накапливать знания и опыт для достижения и воспроизведения профессионального личного лидерства. Следовательно, реализация такого сочетания интересов направлена на капитализацию ими знаний и в краткосрочном, и в долгосрочном периодах.

В то же время необходимо отметить, что состав нефинансовых стейкхолдеров компании не является однородным. В каждой из групп - персонал, менеджмент, клиенты, поставщики, сообщества - существует слой «коллективных действующих лиц» (Клейнер, 2008), активно вовлеченных в формирование интеллектуального или социального капиталов, и, напротив, выпадающих из этого процесса. Поэтому целесообразно выделение стратегических нефинансовых стейкхолдеров, как тех, кто обладает компонентами интеллектуального и социального капиталов и вносит непосредственный вклад в их наращение в ходе операций компании. Однако выделение стратегических нефинансовых стейкхолдеров не означает, что они безусловно способствуют созданию приращения стоимости компании, поскольку вектор изменения стоимости зависит от отсутствия (наличия) гармонизации интересов.

Таким образом, существенные задачи управления стоимостью, нацеленного на создание гармоничной компании, можно суммировать следующим образом:

- идентификация соответствующих границ интересов;

- определение векторов их действия;

- разработка политик, нацеленных на их согласование и балансирование;

- ориентирование на цели наращения стоимости для стейкхолдеров (STVA).

Кроме того, гармоничное развитие как тип предполагает не только согласование сложного множества интересов и влияние на вектор их развития, но и установление баланса между краткосрочными и долгосрочными целями. Следовательно, создание гармоничной компании предполагает, что управленческий цикл подчинен структурированию пространства множественных интересов и достижению в нем баланса. Гармония интересов предполагает устранение разрывов интересов и достижение ситуации, в которой даже при наличии несовпадений интересов их разброс минимален. Снижение степени разброса за счет дополнительных, специальных действий позволит влиять на вектор развития и обеспечивать движение к согласованию интересов в будущем. Таким образом, достижение баланса в новом, более объемном пространстве интересов предполагает спектр воздействий на компанию и ее преобразование. Гармоничной компании должны быть свойственны определенные характеристики, формирующие особое качество ее совокупного капитала.

Поэтому первая характеристика качества капитала гармоничной компании состоит в том, что во множестве интересов ее финансовых и нефинансовых стейкхолдеров более не предполагается безусловного приоритета интересов акционеров компании: выстраивание иерархии интересов по линии «агент (менеджмент) - принципал (акционеры)» создает ограничения в трактовке создания стоимости компании в условиях перехода к инновационной экономике. С этим связано снижение роли агентского конфликта между интересами акционеров (в роли принципала) и наемного менеджмента (в роли исполнителяагента) как парадигмы анализа компании. Гармонизация, достигаемая в пространстве интересов разных категорий стейкхолдеров, нетождественна нахождению баланса интересов агента и принципала, в роли которого выступают финансовые стейкхолдеры. Это более объемное пространство интересов, которое необходимо структурировать, во-первых, для их идентификации; во-вторых, для осуществления требуемых замеров; и, в-третьих, для 
воздействия на систему интересов.

В академических дискуссиях по проблематике стейкхолдерского подхода высказываются разные точки зрения об агентском конфликте. Во-первых, иерархия отношений по линии «агент - принципал» рассматривается как ограниченная трактовка создания стоимости компании в условиях перехода к инновационной экономике, не соответствующая ее новой природе (Blair, 1995; Grandori, Soda, 2003; Aoki, 2003; Kay, Silberson, 1995). Во-вторых, высказывается точка зрения о новой, стейкхолдерской агентской модели, в соответствии с которой менеджмент рассматривается как агент всех, а не только финансовых стейкхолдеров компании (Hill, Jones, 1992, p. 134; Stakeholder Theory, 2010. p.110-111; Милгром, Робертс, 1999).

Корни такой постановки проблемы связаны с работами Б. Бернхайма и М. Уинстона, высказавшими точку зрения о формировании «общего агента» и «общей агентской проблемы» (Bernheim, Whinston, 1985; Bernheim, Whinston, 1986). Необходимость для менеджмента следовать задаче интересов разных групп стейкхолдеров в этом случае рассматривается как позитивная установка, в которой, несмотря на сложности подобных решений, ясно постулируется потребность поиска такого решения в теории и на практике. Противоположная позиция исходит из тезиса об отсутствии у постановки «агент множество принципалов» решения.

Вторая характеристика качества капитала гармоничной компании - формирование нового типа структуры капитала - сбалансированной архитектуры капитала. Истоки подходов к понятию архитектуры компании связаны с работами С. Майерса, предложившего понятие «финансовая архитектура фирмы» (financial architecture) как системы ее корневых структур: собственности, способов финансирования, стимулов и контроля (Myers, 1999). Специфика данного понятия рассмотрена в работах автора (Ивашковская, Степанова, 2009а; Ивашковская, Степанова. 2009б; Ivashkovskaya, Stepanova, 2010).

Архитектура капитала, на мой взгляд, представляет собой соотношение всех форм капитала - финансового, социального и интеллектуального, фиксирующее совокупность их корневых структурных характеристик таких как: собственность на каждую из трех форм капитала; мотивация стратегических финансовых и нефинансовых стейкхолдеров и способы достижения их стратегических намерений в рамках бизнес-модели компании; структура корпоративного контроля над распределением рисков между финансовыми и нефинансовыми стратегическими стейкхолдерами.

Архитектура капитала как особая системная конструкция позволит продвинуться вперед от так называемых «стилизованных моделей» финансовых решений компании о привлечении капитала и формировании его структуры (соотношения заемного и собственного компонентов инвестированного капитала), выплат инвесторам в условиях перехода к инновационной экономике, а также влияния на эффективность компании (Ивашковская, Степанова, 2009б). Архитектура капитала формирует новый срез анализа фирмы не только в части комплекса ее финансовых решений, но и подходов к корпоративному управлению, как механизму решения задачи гармонизации интересов стейкхолдеров. Поэтому она выстраивается с учетом достижения баланса между всеми тремя формами капитала: финансовым, социальным и интеллектуальным.

Это предполагает выполнение нескольких новых условий. При решении задачи максимизации стоимости для финансовых стейкхолдеров-акционеров учет возможных экстерналий, означающих не предусмотренные контрактом последствия для интересов остальных стейкхолдеров в виде изменения их благосостояния, не является предпосылкой принятия решений. Учет таких эффектов осуществляется после принятия решения, рассматриваемого как инструмент достижения цели максимизации стоимости акционерного капитала. Баланс интересов в гармоничной компании, напротив, предполагает обратную последовательность: необходимо структурирование более широкого пространства интересов, их анализ, выявление экстерналий и их учет в процессе разработки самого решения. Таким образом, вовлечение последствий разрабатываемого решения для интересов остальных 
категорий стейкхолдеров должен осуществляться до, а не после его принятия.

Второе существенное отличие в структурировании и балансировании интересов в гармоничной компании связано не только с моментом вовлечения оценивания последствий (экстерналий) в принятие решений, но и с характером самих экстерналий. Экстерналии могут быть позитивными, когда участники трансакции не получают всех выгод и их часть присваивается третьими сторонами; или негативными, когда участники трансакции не несут всех ее издержек. В литературе отмечается, что максимизация стоимости акционерного капитала основана на анализе негативных экстерналий для акционеров (Тамбовцев, 2008).

Балансирование интересов в гармоничной компании основано на учете всех типов экстерналий, как негативных, так и позитивных. Таким образом, второе условие оптимального баланса - структурирование, оценка и учет в принимаемых решениях позитивных и негативных эффектов, относимых к экстерналиям. Третье условие балансирования архитектуры капитала касается критериев идентификации интересов в более широком пространстве. Достижение баланса трех форм капитала предполагает выделение в качестве стратегических нефинансовых стейкхолдеров тех, кто является создателями и обладателями интеллектуального и социального капиталов.

Архитектура капитала гармоничной компании задает третью характеристику качества ее капитала - особую конфигурацию факторов стоимости, в которой выделяется фактор стратегического уровня в форме сети стейкхолдеров, выполняющей роль нового фактора стоимости компании при переходе к инновационной экономике. Конфигурация дерева факторов стоимости - это важная составляющая процесса создания стоимости компании. Дерево факторов стоимости фиксирует иерархию зон, наиболее чувствительных с точки зрения достижения конкурентных преимуществ, подконтрольных системам менеджмента и корпоративного управления в компании, а следовательно, - ключевых для создания потоков выгод.

Традиционно выделяются две группы факторов: финансовые и операционные. В совокупности финансовых факторов агрегированы ключевые причинно-следственные зависимости в операциях компании, ведущие к формированию потоков свободных денежных средств и инвестиционного риска, включающего деловой (коммерческий) и финансовый (риск финансирования). Операционные факторы, напротив, дезагрегируют подобные взаимозависимости, выделяют из их совокупности те, что отражают внутреннее устройство бизнес-процессов в компании, способы их организации. Выделение операционных факторов нацелено на выявление специфических воздействий применительно к компании, ее отдельно взятому подразделению и именно на данном отрезке ее анализа, и, следовательно, привязаны к ее политике (Black, Wright, Davies, 2001, p. 7-8).

В отличие от традиционного взгляда, в гармоничной компании необходимо ввести в дерево факторов стоимости особый фактор стратегического уровня - сеть стейкхолдеров (stakeholder network), в котором фиксируется определенное качество, особое состояние отношений со стейкхолдерами. Если использовать удачный термин Г. Клейнера о «кластерах коллективных действующих лиц» (Клейнер, 2008a, с. 161), то можно определить сеть стейкхолдеров как особую форму организации таких кластеров, которую должна отличать достигаемая в ней ценность и сила (прочность) связей. Стейкхолдерские сети необходимо рассматривать как новый стратегический фактор увеличения стоимости компании, фиксирующий наличие у отношений с заинтересованными группами компании трех особых свойств: гибкости, устойчивости, уникальности.

Взгляд на фирму через призму необходимости строительства стейкхолдерских сетей опирается на концепцию расширенного предприятия (extended enterprise), введенную в работах Дж. Поста, Л. Престона и С. Сакс (Post, Preston, Sachs, 2002; Post, Preston, SauterSachs, 2002). В концепции расширенного предприятия отражено важнейшее явление в современном бизнесе - расширение границ фирмы за счет включения в ее цепочку ценности сетевых взаимодействий. В соответствии с ней понятие «предприятие» включает не только взаимодействия с другими бизнесами, но и отношения с другими стейкхолдерами, которых 
авторы делят на внутренних и внешних. Фирма рассматривается как узел в сетях взаимосвязанных внутренних и внешних стейкхолдеров, которые рождают, поддерживают и наращивают еe способности создания потоков ценностей и стоимости. Поэтому отличительная особенность расширенного предприятия заключается в том, что способности устанавливать и поддерживать эти взаимосвязи внутри сети становятся определяющими для долгосрочного выживания вообще и для достижения эффективности (Post, Preston, Sachs, 2002, p.7).

Разделяя важность взгляда на фирму с позиций расширенного предприятия, считаю необходимым сформулировать положение о выделении сети стейкхолдеров как фактора стоимости компании стратегического уровня в дополнение к тезису о расширенном предприятии. Выделение фактора стратегического уровня основано на следующих аргументах.

Во-первых, как было показано выше, в современной фирме изменилась роль финансового капитала. Фирму теперь неправомерно рассматривать вне контекста социального и интеллектуального капиталов. Возникла новая расстановка сил: финансовый капитал более не является определяющим для долгосрочной конкурентоспособности. Выделения операционных факторов стоимости недостаточно: оно не учитывает новую конфигурацию движущих сил в изменившейся природе конкуренции. Трансформационные способности и формирующиеся на их основе динамические компетенции не сводятся к операционным способностям фирмы и не тождественны им.

Представляется плодотворной точка зрения С. Уинтера о необходимости различать иерархию конкурентных способностей фирмы. В соответствии с его подходом, операционные способности в такой иерархии отнесены к низшему уровню, а динамические к наиболее высокому (Winter, 2003). Чтобы отразить эту кардинальную перемену, в процессе создания стоимости необходимо выделить этот специфический уровень. Стейкхолдерские сети должны рассматриваться как фактор создания стоимости более высокого порядка, обладающий наиболее мощным воздействием на стратегический результат компании и на эффективность исполнения ее корпоративной стратегии. Таким образом, необходимость вычленение данного стратегического фактора стоимости соответствует новым разработкам в теории стратегического менеджмента.

Во-вторых, новые компетенции для конкуренции ведут к ситуации растущей зависимости от невоспроизводимых факторов, к которым и относятся выделенные выше динамические способности. Сказанное ранее означает, что система отношений со стейкхолдерами может превращаться в зону специфической неопределенности - риска отношений с заинтересованными лицами, или стейкхолдерского риска. И в этом заключается второй аргумент в пользу выделения сети стейкхолдеров в отдельный фактор стоимости высокого порядка. Стейкхолдерский риск охватывает: потерю доверия участников сети и в результате устойчивости взаимосвязей; утрату способности к трансформации компетенций под новые возможности для бизнеса и создания новых компетенций. Стейкхолдерский риск, по сути, означает создание препятствий формированию и наращению социального и интеллектуального капиталов в компании, или потерю части социального и интеллектуального капиталов. На уровне качественного анализа компании стейкхолдерский риск должен быть учтен как угроза утраты и снижения динамизма компании, что будет выражаться не только в динамике темпов ее роста, но и в неадекватности реагирования на необходимость реконфигурации коренных компетенций. На уровне количественного анализа этот вид риска будет учтен в форме премии за специфические риски компании.

На эмпирическом уровне первые работы в области влияния стейкхолдерского риска на стоимость компании представлены прежде всего исследованиями социально ответственных инвестиций. Второй вид таких работ - оценка снижения доходности акций компаний, исключаемых из индексов социально ответственных инвестиций. Как отмечают Л. Бечетти, Р. Чичиретти и И. Хасан в исследовании, построенном на изучении изменений доходности акций публичных компаний в связи с исключением этих акций из индекса Domini 400, эти 
события ведут к статистически значимым негативным избыточным доходностям (cumulative abnormal returns, CAR). Избыточные доходности рассчитаны относительно рыночной доходности каждой компании по модели CAРМ. Вывод о возникновении отрицательных значений разности (снижении доходности) оказался устойчивым при проверке в разных спецификациях модели исследования: для разных окон наблюдения, относительно введения параметра сезонности (с помощью дамми-переменных растущего и падающего рынка), относительно альтернативных моделей определения рыночной доходности (Becchetti, Ciciretti, Hasan, 2007). М. Орлицкий и соавторы мета-исследования 52 работ, выполненного в 2003 году, приходят к выводу о том, что стабильные отношения со стейкхолдерами способствуют снижению рисков и росту финансовых результатов (Orlitsky, Schmidt, Rynes, 2003). На практическом уровне к изучению проблемы стейкхолдерского риска подходят разработчики индексов таких инвестиций, концепций управления активами для фондов прямых инвестиций и иных типов инвестиционных фондов.

Третий аргумент в пользу выделения особого фактора стоимости компании стратегического уровня заключается в эффекте синергии. Традиционно синергетические, или умноженные (мультипликативные) эффекты выделяют в случае соединения компаний в операциях слияний, поглощений или, напротив, в ситуациях разъединения бизнесов (выделений, отпочкований). В анализе возможных синергий поэтому традиционно важен факт новой комбинации и новых границ бизнеса, приобретающего набор ресурсов в связи с реконфигурацией существовавших до трансформации компании границ. Однако надо подчеркнуть, что стейкхолдеры компании без формальной реконфигурации компании как в направлении ее расширения, так и в направлении ее сужения создают эффект синергии, если качество отношений с ними соответствует их ожиданиям.

К. Лидбитер подчеркивает, что заинтересованные лица компании способны разделять риски компании, что продвигает бизнес-инновации и увеличивает гибкость реагирования на изменения в конкурентной среде (Leadbeater, 1999, p. 152). Сеть стейкхолдеров как особое качество состояния взаимодействия компании с ними способна создавать операционную синергию в двух ее формах: экономию на гибкости (охвате) и возможности роста. Формирование сетевых связей со стейкхолдерами также означает изменение границ компании, но без формальных процедур ее трансформации. Учитывая сказанное о сети стейкхолдеров как факторе стоимости высокого порядка, необходимо подытожить его существенную особенность. Данный фактор необходимо расценивать как условие достижения конкурентной устойчивости бизнеса, и поэтому действие этого фактора необходимое условие устойчивости роста стоимости для всех - финансовых и нефинансовых стейкхолдеров.

Таким образом, качество капитала гармоничной компании необходимо характеризовать, выделяя стратегический уровень создания стоимости путем формирования устойчивых сетей стейкхолдеров. Наличие таких сетей рассматривается как способ эффективного использования социального и интеллектуального капиталов.

Отмеченное выше формирование системного контура нефинансового капитала означает существенные сдвиги в понимании механизмов создания стоимости компании, связанные со смещением усилий от присвоения ресурса до процесса создания продукта к созиданию самого ресурса в виде интеллектуального и социального капиталов в самом процессе создания продукта. Это вносит существенные отличия в понимание характера взаимоотношений со стейкхолдерами - носителями данных форм капитала. Поэтому в финансовом анализе компании необходимо искать решения для отражения с помощью его инструментов нового типа структуры капитала - архитектуры капитала, которая фиксирует содержательную характеристику гармоничной компании. Архитектура капитала формирует новый срез анализа фирмы, предполагает новое стоимостное мышление и изменения в подходах к корпоративному управлению как механизму решения задачи гармонизации интересов стейкхолдеров. Таким образом, концепция гармоничной компании образует основу для новых подходов к управлению, ориентированному на создание стоимости 
компании, для развития нового стоимостного мышления и системы инструментов финансовых измерений и финансового анализа.

\section{Список литературы}

1. Ивашковская И.В. Модель стратегического стоимостного анализа фирмы // Экономическая наука современной России. 2008а. № 3. С. 115-127.

2. Ивашковская И.В. Стратегический мониторинг создания стоимости для всех стейкхолдеров компании // Вестник Финансовой академии. 2008б. № 3. С. 69-85.

3. Ивашковская И.В. Финансовые измерения корпоративных стратегий. Стейкхолдерский подход. М.: ИНФРА-М, 2008в.

4. Ивашковская И.В., Степанова А.Н. Структура собственности и ее влияние на стратегическую эффективность компаний // Финансы и бизнес. 2009а. № 3. С. 1-22.

5. Ивашковская И.В., Степанова А.Н. Финансовая архитектура фирмы: структура собственности и корпоративная эффективность на растущих рынках капитала // Модернизация экономики и общественное развитие: в 3 кн. / отв. ред. Е.Г. Ясин; Гос. ун-т - Высшая школа экономики. М.: Изд. дом ГУ - ВШЭ, 2009б. С. 180-187.

6. Клейнер Г. Стратегия предприятия. М.: Дело, 2008.

7. Милгром П., Робертс Дж. Экономика, организация и менеджмент: в 2 т. СПб.: Экономическая школа, 1999.

8. Тамбовцев В.Л. Стейкхолдерская теория фирмы в свете концепции режимов собственности // Российский журнал менеджмента. 2008. Т. 6, № 3. С. 3-26.

9. Aghion, P., Bolton, P. (1992), An Incomplete Contracts' Approach to Financial Contracting, Review of Economic Studies, 3(59) (1992) 473-494.

10. Aguilera, R.V., Cuervo-Cazurra, A. (2004), Codes of Good Governance World-Wide: What is the Trigger? Organization Studies, 3(25) (2004) 415-443.

11. Aguilera, R.V., Jackson, G. (2003), The Cross-National Diversity of Corporate Governance: Dimensions and Determinants, Academy of Management Review, 3(28) (2003) 447-465.

12. Aoki, M. (2003), Comparative Institutional Analysis of Corporate Governance, Corporate Governance and Firm Organization / ed. by A. Grandori. Oxford; N.Y.: Oxford University Press.

13. Asher, C.C., Mahoney, J.M., Mahoney, J.T. (2005), Towards a Property Rights Foundation for a Stakeholder Theory of the Firm, Journal of Management and Governance, 1(9) (2005) 5-32.

14. Baker, G., Gibbons, R., Murphy, K.J. (2001), Bringing the Market inside the Firm? American Economic Review, 2(91) (2001) 212-218.

15. Becchetti, L., Ciciretti, R., Hasan, I. (2007), Corporate Social Responsibility and Shareholder's Value: An Event Study Analysis: Federal Reserve Bank of Atlanta Working Paper, Atlanta, 6 (2007).

16. Bernheim, D., Whinston, M. (1986), Common Agency, Econometrica, 4(54) (1986) 923942.

17. Bernheim, D., Whinston, M. (1985), Common Marketing Agency as a Device for Facilitating Collusion, RAND Journal of Economics, 2(16) (1985) 269-281.

18. Black, A., Wright, Ph., Davies, J. (2001), In Search of Shareholder Value. Managing the Drivers of Performance. Prentice Hall.

19. Blair, M., Stout, L.A. (1999), A Team Production Theory of Corporate Law, Virginia Law Review, 2(85) (1999) 247-328.

20. Blair, M.M. (1995), Ownership and Control: Rethinking Corporate Governance for the 21 Century, Washington, DC: Brookings Institution.

21. Charreaux, G., Desbrieres, P. (2001), Corporate Governance: Stakeholder Value Versus Shareholder Value, Journal of Management and Governance, 2(5) (2001) 107-128.

22. Deakin, S. (1995), The Coming Transformation of Shareholder Value, Corporate 
Governance, 1 (13) (1995) 11-18.

23. Donaldson, T., Preston, L.E. (1995), The Stakeholder Theory of the Corporation: Concepts, Evidence, Implications, Academy of Management Review, 1(20) (1995) 85-91.

24. Frooman, J. (1999), Stakeholder Influences Strategies, Academy of Management Review, 2(24) (1999) 191-205.

25. Grandori, A., Soda, G. (2003), Governing with Multiple Principals: a Framework and a Research on Italy, Corporate Governance and Firm Organization / ed. by A. Grandori. Oxford; N.Y.: Oxford University Press.

26. Handy, C. (1997), The Citizen Corporation, Harvard Business Review, 5(75) (1997) 7-8.

27. Hart, O., Moore, J. (1990), Property Rights and the Nature of the Firm, Journal of Political Economy. 6(98) (1990) 1119-1158.

28. Hill, C.W.L., Jones, T.M. (1992), Stakeholder Agency Theory, Journal of Management Studies, 2(29) (1992) 131-154.

29. Ivashkovskaya, I., Stepanova, A. (2010), Does Strategic Corporate Performance Depend on Corporate Financial Architecture? Empirical Study of European, Russian and Other Emerging Market's Firms, Journal of Management and Governance. Online - First. February (2010) DOI 10.1007/s 10997-010-9132-7 www.springerlink.com/content/1385$3457 / ? \mathrm{k}=$ DOI.

30. Kay, J., Silberson, A. (1995), Corporate governance, National Institute Economic Review, 84 August (1995) 84-97.

31. Leadbeater, C. (1999), Living on Thin Air. L.: Viking.

32. Luoma, P., Goodstein, J. (1999), Stakeholders and Corporate Boards: Institutional Influences on Boards Composition and Structure, Academy of Management Journal, 5(42) (1999) 553-563.

33. Mitchell, R.K., Agle, B.R., Wood, D.J. (1997), Towards the Theory of Stakeholder Identification and Salience: Defining the Principle of Who and What Really Counts, The Academy of Management Review, 4 (22) (1997) 853-896.

34. Modern Company Law for a Competitive Economy: Developing Framework. L.: DTI, 2002.

35. Myers, S. (1999)Financial Architecture, European Financial Management. 2 (5) (1999) 133141.

36. Orlitsky, M., Schmidt, F.L., Rynes, S.L. (2003), Corporate Social and Financial Performance: A Meta-analysis, Organization Studies, 3(24) (2003) 403-441.

37. Pajunen, K. (2006), Stakeholder Influence on Organizational Survival, Journal of Management Studies, 6(43) (2006) 1261-1288.

38. Post, J., Preston, L.E., Sachs, S. (2002), Managing Extended Enterprise: The New Stakeholder View, California Management Review, 1(45) (2002) 6-28.

39. Post, J.E., Preston, L.E., Sauter-Sachs, S. (2002), Redefining the Corporation, Stakeholder Management and Organizational Wealth. Stanford Business Books.

40. Principles of Stakeholders Management / Clarkson Center of Business Ethics. University of Toronto, 1999.

41. Stakeholder Capitalism / ed. by G. Kelly, D. Kelly, A. Gamble. L.: Macmillan, 1997.

42. Stakeholder Theory. The State of the Art / Freeman R.E., Harrison J.S., Wicks A.C., et al. Cambridge University Press, 2010.

43. The Corporation and Its Stakeholders / ed. by M.B.E. Clarkson. University of Toronto Press, 1998.

44. Winter, S.G. (2003), Understanding Dynamic Capabilities, Strategic Management Journal, 10(24) (2003) 991-995.

45. Zingales, L. (2000), In Search of New Foundations, The Journal of Finance. 4(55) (2000) $1623-1653$. 